\title{
Present and future of secondary prevention after an acute coronary syndrome
}

\author{
Pierre-Frederic Keller • Sebastian Carballo • \\ David Carballo
}

Received: 6 July 2011 / Accepted: 25 September 2011 /Published online: 25 October 2011

(C) European Association for Predictive, Preventive and Personalised Medicine 2011

\begin{abstract}
Despite a marked improvement of in-hospital outcome of patients with Acute Coronary Syndrome (ACS), long-term outcome remains poor. There remains a high risk of complications, Non ST-Elevation ACS (NSTE-ACS) patients being at higher risk than those with ST-elevation ACS, in part due to more diffuse coronary artery disease. Whether with conservative medical management or an early invasive approach, of which they less frequently benefit, NSTE-ACS patients are less frequently treated according to guidelines. Therapeutic adhesion within the months following hospital discharge is low and associated with an increase in one-year mortality. The next step in the improvement of care of ACS patients will be to use multi-dimensional prevention programs that use didactic information tools and improve patient motivation, aimed at reinforcing the use of guidelines, promoting in-hospital therapeutic education, creating patienthealth care provider partnerships and including discharge programs that ensure the prescription of recommended therapies.
\end{abstract}

Keywords Acute coronary syndrome - Education . Prevention · Personalized medicine

\section{Introduction to the pathogenesis and treatment strategies of acute coronary syndromes}

Coronary artery disease is the result of the development of coronary atherosclerosis. The pathogenesis is complex and linked to the proliferation of smooth muscle cells, synthesis of connective tissue matrix, focal accumulation of monocytes/

P.-F. Keller $(\bowtie) \cdot$ S. Carballo $\cdot$ D. Carballo

Cardiology Division, University Hospitals,

CH-1211 Geneva, Switzerland

e-mail: Pierre-frederic.keller@hcuge.ch macrophages, infiltration of lymphocytes and various levels of intracellular and extracellular lipid accumulation. Atherosclerosis can be considered to be a response to injury, with the major risk factors being elevated blood pressure, pathological lipid profiles, cigarette smoking, diabetes mellitus, family history, age and gender, some of these being modifiable. Atherosclerosis is a chronic disease that can affect all arteries, and in particular the cerebral, cardiac, renal and peripheral ones. The clinical manifestations are a consequence of the subsequent progressive or acute occlusion of these arteries and include coronary heart disease, cerebrovascular disease and peripheral arterial disease. With regard to cardiac manifestations, the disease ranges from an asymptomatic state to potential sudden death. Angina pectoris (chest pain) often presents in patients who develop progressive obstruction of their coronary arteries, referred to as stable coronary artery disease. Acute coronary syndromes (ACS) cover the constellation of acute clinical presentations linked to the rupture of an unstable atherosclerotic plaque and the subsequent platelet aggregation and thrombus formation that acutely and often completely occludes a coronary artery. ACSs have been categorized using clinical, elecrocardiographical and biological criteria. Thus clinical presentations associating elevation of biomarkers of myocardial injury with electrocardiographic ST segment elevation are referred to as ST elevation myocardial infarction (MI) (STEMI), those without ST elevation are referred to as Non ST-elevation MI (NSTEMI or NSTE-ACS) and when the syndrome is accompanied by neither ST elevation or biomarker elevation, it is referred to as Unstable Angina (UA). The overall therapeutic aim in all circumstances is to reestablish coronary patency and thus balance myocardial demand and supply of oxygenated blood. Revascularization is primarily achieved using percutaneous coronary interventions (PCI) and angioplasty in association with powerful anti-thrombotic agents and subsequent clinical and electrocardiographic monitoring. Secondary 
cardiovascular prevention is essential in the subsequent management phase and requires patient and healthcare provider education and the application of international therapeutic guidelines to ultimately ensure patient therapeutic adhesion.

\section{Introduction}

The prognosis of acute coronary syndrome (ACS) has much improved in recent years as a result of advances in the early initiation of anti-thrombotic therapies, early invasive management and the development of coronary care units. Nevertheless, the risk of recurrence of cardiovacular complications after an ACS remains as high as $15 \%$ at 12 months [1]. International guidelines recommend pharmacologic and lifestyle interventions to reduce recurrent events in patients with coronary and other atherosclerotic vascular disease. However, audits of practice reveal suboptimal control of cardiovascular risk factors and under use of evidence-based cardiovascular medication [2]. Consequently the lack of in-hospital initiation of evidence-based cardiovascular medications seems to alter long-term patient compliance and clinical outcomes [3, 4]. In addition, 30\% of patients stop their treatment either partially or totally within 30 days after hospital discharge with a significant increase in 1-year mortality [5]. In the United States, projects have tested pragmatic interventions targeting an increase in prescription rates by physicians and/or long-term medication adherence by patients [6-10]. In Europe, Wood et al. recently showed an association between healthier lifestyle and improvements in cardiovascular risk factor control for patients with coronary heart disease who benefitted from a nurse coordinated, multidisciplinary, family-based, ambulatory program [11]. The benefit of in-hospital multidimensional interventions for patients after an ACS was demonstrated in a recent review and meta-analysis [12]. In this meta-analysis, secondary prevention programs were categorized as patient-, health care provider- (HCP) and system-level interventions [13]. It was demonstrated that multidimensional interventions, targeting the patients, the provider and the health care system increased prescription rates of proven efficacious medication and seemed to reduce mortality and recurrent ACS [12, 14]. Data from the international GRACE registry showed various prescription rates of cardiovascular medication according to regions of the world [15]. Variations across countries might be due to national quality improvement strategies and probably cultural differences as well. To date, there is no systematic prospective data collection in the setting of a nation-level multidimensional quality improvement strategy or incentives to improve the care of patients with coronary heart disease. Multi- dimensional quality improvement programs should be implemented to firstly improve the application of recommended therapies for patients admitted to the hospital for an ACS, secondly, to improve patient therapeutic education, and finally to improve the continuation of education and recommended medical management for long-term secondary prevention in a health care system network including acute care hospitals, rehabilitation centers and outpatient physicians.

\section{ACS patients have a high risk of recurrent cardiovascular events and of mortality}

Overall mortality rates from the onstart of myocardial injury before hospital admission until discharge is difficult to determine because of several clinical and epidemiological limitations such as the frequent occurrence of silent ischemia or silent MI, the consistent rate of pre-hospital sudden death, and the varying methods and definitions used in the diagnosis of death and its etiology. Population studies have consistently shown that overall case fatality rates of patients with presumed MI or ACS in the first 30 days is higher than $50 \%$, and about half of these deaths occur within the first $2 \mathrm{~h}$ [16]. Pre-hospital mortality seems to have modestly decreased over the last decades in contrast with in-hospital mortality after an ACS, which was markedly decreased thanks to monitoring in coronary care units, improvement of in-hospital care including urgent reperfusion using thrombolytic therapy and primary percutaneous coronary intervention (PCI) in STEMI, new anti-thrombotic therapies, the use of more sensitive biomarkers of risk such as troponin, and a better stratification of the predicted risk with an early invasive strategy for intermediate and higher risk NST-ACS patients [17]. The short-term mortality rate after an ACS is markedly higher for patients with ST-elevation myocardial infarction (STEMI) than for patients with non ST-elevation myocardial infarction (NSTEMI) itself higher than that of patients with unstable angina (UA) [18]. Nevertheless, Terkelsen et al. demonstrated a similar favorable trend of mortality for patients admitted to hospital for STEMI and NSTEMI between 1994 and 2006. Indeed after hospital admission, hospital mortality of patients admitted for MI (STEMI and NSTEMI) fell from 10.4\% to $6.3 \%$, and mortality of patients with STEMI fell from $11.5 \%$ to $8.0 \%$, and of patients with NSTEMI from $7.1 \%$ to $5.2 \%$ (all $P<0.0001$ ). After adjustment for baseline characteristics, hospital mortality fell among all patients by $23.6 \%$ (odds ratio (OR) $0.764,95 \%$ CI $0.744-0.785$ ), STEMI by $24.2 \%$ (OR $0.758,0.732-0.784$ ), and NSTEMI by $22.6 \%$ (OR 0.774 , $0.741-0.809$ ), all $P<0.001$. Similarly a significant decrease of mortality rate was also demonstrated between two time periods: 2001-2002 and 2003-2004 for patients admitted for NSTEMI and UA due to the implementation of more 
recent guidelines, which include more aggressive antithrombotic therapy associated with early invasive approaches or coronary angiography and subsequent PCI $[19,20]$. Of note this study demonstrated the favorable impact of the implementation of new guidelines on the outcome of patients in the setting of NSTE-ACS.

Paradoxically, long-term mortality rate is higher for patients with non ST-elevation ACS (NSTE-ACS) than those with STEMI as it was shown in the data published by Terkelsen et al.: from hospital admission, 1 year mortality was $31 \%$ for NSTEMI patients, $21 \%$ for STEMI patients, and $55 \%$ for MI associated with a bundle branch block $(P<0.001)$ (Fig. 1) [21]. Interestingly, one-month mortality has since been reduced to a much lower level of 4-6\% [22, 23] or even less [24] in large-scale randomized trials compared to registries suggesting that patients included in randomized trials are at lower risk when compared with those observed in the real world [25]. All these data demonstrate that inhospital and 30-day mortality has been markedly decreased over the last decades due in part to improvements in medical therapies and to more aggressive earlier invasive interventions. Short-term mortality rate is higher in STEMI than in NSTE-ACS, however this difference is already abolished after 1 year and the decrease of one-year mortality rate over the years is less pronounced than the decrease of 30-days mortality rate. These data summarize the favorable impact of in-hospital management of the acute phase of ACS and the weaker impact of therapeutic progresses on long-term outcome after an ACS. Long-term outcome of patients after an ACS is mainly dependent on the chronic nature of atherosclerosis, which exposes ACS patients to a high risk $(15 \%)$ of recurrent cardiovascular events at 1 year [1]. In the past, restenosis was a reason for recurrent target lesion revascularization after PCI in $20-30 \%$ after stenting procedures without significant impact on mortality, however the

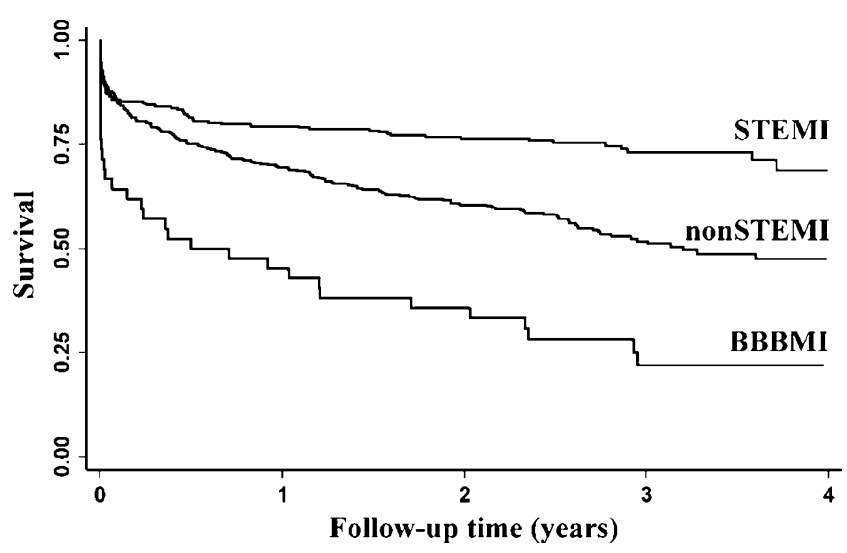

Fig. 1 Kaplan-Meier survival curves after STEMI, nonSTEMI and BBBMI. With permission of Terkelsen et al. [21]. STEMI: ST-Elevation Myocardial Infarction; nonSTEMI: non ST-Elevation Myocardial Infarction; BBBMI: bundle Branch Block related Myocardial Infarction use of drug-eluting stents gave a definite solution to this issue [26]. Recurrent cardiovascular events after an ACS are therefore today mainly explained by the natural history of atherosclerosis with plaque progression and rupture. Indeed Cutlip et al. demonstrated even before the era of drug-eluting stents that after 2 years, the rate of stable and unstable recurrent coronary events occurred 5 times more frequently in other coronary arteries than that involved during the initial ACS [27].

\section{In-hospital underuse of recommended therapies after an ACS}

Unfortunately, important gaps exist between international recommendations for the management of patients with ACS and atherosclerosis and everyday practice (Fig. 2) [28]. Of note, if treatment in secondary prevention of atherosclerosis after a MI is not initiated at the time of discharge, the likelihood of ever receiving treatment is low. On the other hand if medical therapy in secondary prevention after MI is started early, most patients adhere to treatment on the long term. Furthermore, the prescribed doses of medications are usually and substantially lower than those recommended and seldom adjusted during long-term therapy [29, 30]. Interestingly, patients admitted for an ACS treated medically are less likely to be treated according to guidelines than those who benefit from an invasive management [31]. Therefore reinforcement of the application of guidelines in ACS and secondary prevention must be implemented to increase the rate of prescription of recommended therapies during the hospital stay of patients admitted for an ACS. Such programs have been successfully implemented for example the Cardiac Hospitalization Atherosclerosis Management Program (CHAMP), which was developed and implemented at a university-affiliated

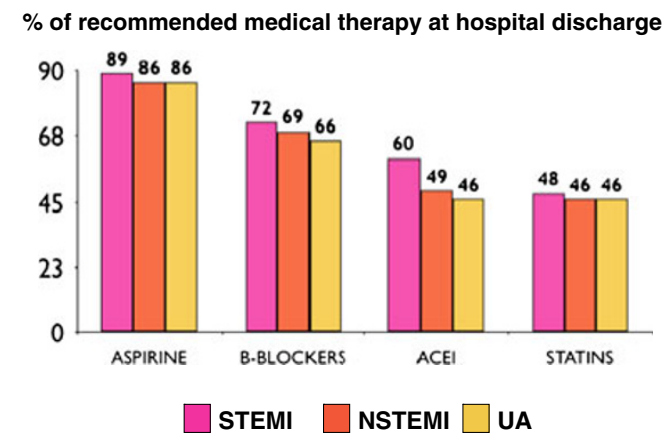

Fig. 2 Prescription rate of recommended therapies at discharge according with each category of acute coronary syndrome. According with the data of Steg et al. [28]. STEMI : ST-Elevation Myocardial Infarction; nonSTEMI: non ST-Elevation Myocardial Infarction; UA: Unstable Angina 
teaching hospital [7]. The program focused on initiation of aspirin, cholesterol-lowering medication titrated to achieve the recommended target level of LDL-cholesterol, betablocker, and angiotensin-converting enzyme (ACE) inhibitor therapy in conjunction with lifestyle change counseling in patients with established coronary artery disease before hospital discharge. A clinical study assessed the impact of the CHAMP program on secondary prevention medication utilization in a before/after design including 256 and 302 patients respectively in each time period. Aspirin use at discharge improved from $68 \%$ to $92 \%(p<0.01)$, betablocker use improved from $12 \%$ to $62 \%(p<0.01)$, ACE inhibitor use increased from $6 \%$ to $58 \%(p<0.01)$, and statin use increased from $6 \%$ to $86 \%(p<0.01)$. This increased use of treatment persisted during subsequent one-year follow-up. There was also a significant increase in patients achieving LDL cholesterol $<100 \mathrm{mg} / \mathrm{dl}(6 \%$ vs $58 \%, p<0.001)$ and a reduction in recurrent 1 -year MI $(7.8 \%$ vs $3.1 \%, p<0.05)$, total mortality ( $7 \%$ vs $3.3 \%, p<0.05)$, and cardiac mortality $(5.1 \%$ vs $2 \%, p<0.05)$ [7].

The American College of Cardiology, in partnership with the Michigan quality improvement organization and the Greater Detroit Area Health Council, initiated the American College of Cardiology's Guidelines Applied in Practice (GAP) in Michigan in 1999 to improve the quality of care after MI by reinforcing the application of guidelines and by using standard admission ordersets and standard discharge contracts associated with strong physician and nurse administrative case management controls [32, 33]. This pilot program included 2,857 patients admitted for MI (1,368 patients before and 1,489 patients after program implementation in a before/after design) and showed a $21 \%$ to $26 \%$ reduction in mortality, particularly at 30 days (odds ratio of GAP to baseline $0.74 ; 95 \%$ CI 0.59 to $0.94 ; p=0.012$ ) and 1 year (odds ratio $0.78 ; 95 \%$ CI 0.64 to $0.95 ; p=0.013$ ) [10]. In addition to such quality improvement programs based on medical therapy, lifestyle change programs initiated at hospital have also demonstrated significant impact on outcomes after an ACS. In-hospital non-pharmacologic and smoking cessation counseling interventions seemed to be effective in a systematic review of randomized controlled trials including patients with coronary artery diseases $[34,35]$. Importantly, cardiac rehabilitation programs are an important corner stone in the educational process of care after an ACS. Indeed Taylor et al. [36] demonstrated in a meta-analysis including 48 trials with a total of 8940 patients that phase 2 cardiac rehabilitation program reduced all-cause mortality by $20 \%$ (OR 0.80 ; $95 \%$ CI: 0.68 to 0.93 ) and cardiac mortality by $26 \%(\mathrm{OR}=0.74 ; 95 \%$ CI: 0.61 to 0.96$)$. Therefore phase 2 cardiac rehabilitation is a class 1 recommendation according to international guidelines [37]. Unfortunately and despite these robust recommendations only $30 \%$ of patients after an ACS benefit from a phase 2 cardiac rehabilitation program [38]. Referring patients to cardiac rehabilitation centers is one major intervention of the numerous interventions recommended for patients after an ACS. Of note cardiac rehabilitation programs reinforce the use of recommended therapies and of therapeutic education in secondary prevention.

\section{Lack of medication adherence after an ACS}

Therapeutic adherence rates to medication are typically higher among patients with acute disease than those with chronic illness. Furthermore, adherence rates among patients with chronic conditions are disappointingly decreased over time, dropping most dramatically after the first 6 months of therapy [39-41]. For example, approximately half of elderly patients receiving a statin therapy for dyslipidemia in primary and secondary prevention will discontinue their medication within 6 months after starting the medication [42].

Taking into account the definition of the International Society for Pharmacoeconomics and Outcome Research, medication compliance or medication adherence refers to the act of conforming to the recommendations of medical prescription with respect to timing, dosage, and frequency of medication taking [40]. In summary medication adherence is the extent to which a patient acts in accordance with the prescribed dosing regiment. The unit of measure is administered doses per defined period of time, reported as the proportion of prescribed doses taken in the prescribed time interval (\%) (Fig. 3). Medication persistence is defined as "the duration of time from initiation to discontinuation of therapy", independently of the regiment dose or frequency of the medication (Fig. 3) [40].

Noncompliant behavior is a critical issue in the care of patients with chronic disease. Noncompliant behavior is a consequence of several parameters (Table 1) and especially of a physician-patient alliance failure. The impact of the lack of therapeutic adhesion was noted in observational studies [5] and also noticed in controlled randomized trials

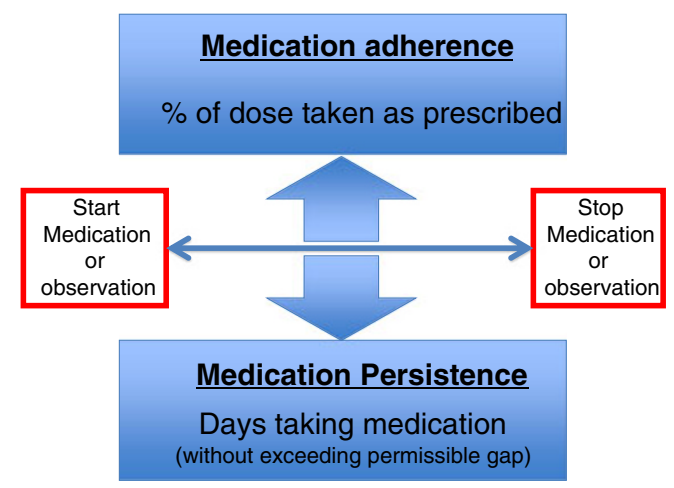

Fig. 3 Definitions of medication adherence and persistence proposed by the Issues and Methods Definitions Working Group of the Medication Compliance and Persistence Special Interest Group. According with the publication of Cramer et al. [40] 
Table 1 Predictors of noncompliant behavior according with illness and care-related predictors as well as patient related predictors with their corresponding references

Predictors of noncompliant behavior for the management of chronic diseases

References

Illness and care-related predictors

- Complexity of treatment

- Inadequate follow-up or discharge planning

- Treatment of asymptomatic disease

- Side effects of medication

- Poor provider-patient relationship

- Patient's lack of belief in benefit of treatment

- Presence of barriers to care or medications

- Cost of medication, unsufficient reimbursement, or both

- Missed appointments

Patient-related predictors

- Presence of cognitive impairment or psychological problems

$[43,46,47,52]$

such as depression

- Patient's misinterpretation or lack of insight into the illness

$[45,48]$

showing average adherence rates of only $43-78 \%$ among patients receiving medication for chronic diseases [53]. Importantly, patients included in randomized trials benefit from a close monitoring of medication following the quality and safety control of such studies and this should be in favor of more favorable therapeutic adhesion rates. In the modern era, there have been major changes in physicianpatient interaction and agreement. The traditional authoritarian approach of the caregiver has evolved towards a collaborative partnership with the patient in order to jointly define the modalities of the medical management of health, disease and preventive medical and lifestyle interventions. Noncompliant behavior is most often the result of a communication failure consecutive to lack of consideration of several important psychosocial dimensions of individuals facing chronic disease. These psychosocial dimensions include the self-representation of illness and the benefit of its medical management, the belief of such a benefit, the confidence in medical management and in the caregiver, and finally in the motivation to change daily habits by taking long-term medication and by changing lifestyle, which implies important behavior changes. Therefore these changes have to be discussed with the patient and the discussion needs to be interactive with a common objective of patient-caregiver partnership instead of a simple recommendation of treatment. The result should be that the patient himself decides on the long-term medical management of his chronic disease. Therapeutic education of the patient and motivational interviewing has been developed to help patients and caregivers to change and evolve towards a collaborative partnership, which consists of care centered on the patient. A widely used current model in therapeutic education of the patient is that of shared decision making, in which physician and patient discuss, negotiate and finally agree on the medical condition and on problem solving.

\section{The future for patients admitted to the hospital with an ACS: use of multi-dimensional secondary prevention programs}

As a result of the benefit and safety of an early invasive strategy in the care of patients with high risk ACS and thanks to a trans-radial PCI approach, the duration of hospital stay has decreased dramatically during the last decade. Indeed even after administration of an intensive anti-thrombotic therapy including glycoprotein IIb-IIIa (GPIIbIIIa) receptor inhibitors, a same-day home discharge after PCI via trans-radial approach has been demonstrated to be safe and with a markedly favorable economic impact in part due to the marked reduction in bleeding complications $[54,55]$. Therefore the future of Diagnostic-Related Group (DRG) reimbursement for patients admitted to hospital for an ACS will be based on recommended international guidelines [37], which recommend at least $24 \mathrm{~h}$ of hospitalization after PCI of the culprit lesion and also be based on the more recent data about same-day safety discharge after PCI under GPIIbIIIa receptor inhibitors [54]. Consequently hospital stay will shorten in the future. This will reduce the time period for the educational process of patients and might decrease its quality in the actual context of suboptimal care of patients with an ACS as it has been described above.

The future challenges in the care of patients with ACS will be to sensitize physicians about the high long-term risk 
of all patients having suffered from an ACS, to improve the quality of care by increasing the rate of recommended prescriptions according to guidelines, to improve in-hospital education of care caregivers in the acute and long-term treatments of patients with an ACS, to improve in-hospital education of the patient and finally to improve communication between hospitals, outpatient physician practices and cardiac rehabilitation centers. These challenges will be of primary importance in the future of hospital cost reimbursement.

The first essential step to achieve this complex objective in quality improvement for patients with an ACS will be to sensitize caregivers, including cardiologists, of the real risk of ACS patients and to measure local practice of care for these patients. Similarly to the recommended multidisciplinary work-up necessary to perform primary PCI in tertiary hospitals [56], a local inventory of practice and outcome should first be planned. After the assessment of this local analysis of care and outcome of patients with an ACS, a multidisciplinary improvement program should be developed including all caregivers from nurses, internists, cardiologists (non-invasive and invasive), specialists in therapeutic education, nurses assistants, and physiotherapists. The program should answer the critical issues discussed above about the gap between an ideal situation and the reality of care of patients with an ACS. To achieve this objective, we have developed a multidimensional prevention program after an Acute Coronary Syndrome (ELIPS). The ELIPS program has been deployed in all university hospitals in Switzerland, under the direction of the Geneva University Hospitals.

The ELIPS program aims at improving the acute care of patients with an ACS and long-term secondary prevention of atherosclerosis by using a multi-dimensional or multilevel approach. First of all, a reinforcement of guidelines has been implemented at the caregivers-level and associated with a discharge program of care to ensure the use of the recommended therapies and lifestyle recommendation (patient-level intervention). This discharge program was designed based on the GAP program [33]. This program includes a discharge card which is given to the patient and allows for discussion with his family physician as well as his cardiologist (system-level intervention). In addition, information sessions have been given throughout the

Table 2 Summary of components of the ELIPS ${ }^{\circledR}$ program

\begin{tabular}{|c|c|c|c|}
\hline Tools & Components & Providers & Time of application \\
\hline Educational program & $\begin{array}{l}\text { Motivational interviews or brief } \\
\text { motivational interventions }\end{array}$ & $\begin{array}{l}\text { Medical staff of all hospitals } \\
\text { involved in the care of patients } \\
\text { with coronary artery disease: } \\
\text { CCU, Cathlab, Cardiology } \\
\text { division, cardiac rehabilitation }\end{array}$ & $\begin{array}{l}\text { From the admission until } \\
\text { the end of the cardiac } \\
\text { rehabilitation with } \\
\text { encouragement of } \\
\text { outpatient consultation } \\
\text { in motivational interviews } \\
\text { about cardiovascular risk } \\
\text { factors }\end{array}$ \\
\hline Film (DVD) & $\begin{array}{l}\text { The history of a patient admitted } \\
\text { with an ACS: the acute phase } \\
\text { and the need of secondary } \\
\text { prevention of a chronic disease }\end{array}$ & $\begin{array}{l}\text { - Diffusion: hospital including } \\
\text { CCU, Cardiology division } \\
\text { and/or cardiac rehabilitation. } \\
\text { - Distribution: family doctor } \\
\text { or cardiologist (campaign } \\
\text { of distribution) }\end{array}$ & $\begin{array}{l}\text { According to the demand of } \\
\text { the patient }\end{array}$ \\
\hline Interactive wallchart & $\begin{array}{l}\text { Information about cardiovascular risk } \\
\text { factors, lifestyle counselling and } \\
\text { questions, self-assessment of } \\
\text { cardiovascular risk factors }\end{array}$ & $\begin{array}{l}\text { Shown in the cardiology } \\
\text { division and in the cardiac } \\
\text { rehabilitation center }\end{array}$ & After the discharge of the ICU \\
\hline Flyers & $\begin{array}{l}\text { Similar information as on the } \\
\text { wallchart }\end{array}$ & $\begin{array}{l}\mathrm{CCU} \text {, Cardiology department, } \\
\text { Cardiac rehabilitation, website }\end{array}$ & $\begin{array}{l}\text { CCU. Cardiology department, } \\
\text { cardiac rehabilitation, website }\end{array}$ \\
\hline \multicolumn{4}{|l|}{ Websites: } \\
\hline $\begin{array}{l}\text { www.elips.ch } \\
\text { www.elips-e-learning.org }\end{array}$ & $\begin{array}{l}\text { - Information about cardiovascular } \\
\text { risk factors, lifestyle counseling } \\
\text { and questions, self-assessment } \\
\text { of cardiovascular risk factors. } \\
\text { - E-learning in motivational } \\
\text { interviews and brief interventions } \\
\text { for medical staff. }\end{array}$ & - Family doctor & In and out of the hospital \\
\hline
\end{tabular}

$C C U$ coronary care unit 
country to inform caregivers of referring hospitals and outpatient physicians of the implementation of the overall ELIPS program. Secondly, an educational process has been developed taking into account the time limitation due to the briefness of hospital stay in the setting of ACS and also the limited resources for education of acute patients in public hospitals. Because of these limitations, the most suitable educational approach in the setting of ACS was motivational interviewing. We therefore developed a program of motivational interviewing including an e-learning (www.elips-elearning.org) and a face-to-face training course dedicated to nurses and in-hospital physicians (care-givers-level intervention). Finally numerous and novel ACS and atherosclerosis information tools were created in a uniform and complementary manner, dedicated to patients and healthcare providers (patient-level intervention as well as healthcareproviders-level intervention). These information tools include a DVD film, a website (www.elips.ch), a smartphone application, flyers, and an interactive wallchart for hospital and rehabilitation center use (Table 2). All tools including the motivational interviewing e-learning were translated into the main spoken languages in Switzerland, namely English, German, French and Italian. Moreover, the tools were validated in all languages by all Swiss university hospitals, by a university legal department and by a patient representative commission of validation.

A clinical study is ongoing to assess the efficacy of the ELIPS program (Clinicaltrial.gov: NCT01075867) supported by the Swiss National Science Foundation in a global translational research project of ACS (www.spum-acs.ch). In the context of this quality improvement program, including a media campaign and a training process with potential "contamination", the evaluation study has a before-after design. One thousand two hundred control patients were included between 2009 and the deployment of ELIPS in November 2010 and the same number of patients will be included in the post-implementation phase. The results of the study are expected for 2013. The primary endpoint will be the recurrence of cardiovascular events (cardiovascular death, non-fatal myocardial infarction, cerebrovascular attack, transient cerebral ischemic accident and lower limb ischemia) at 1 year. Events and endpoints will be assessed by an independent adjudication committee. Numerous sub-studies will assess the impact of the program on therapeutic adhesion, the effect of a tobacco cessation program, and the effect on quality of life and numerous biological markers.

\section{Conclusions}

Despite the marked improvement of the in-hospital outcome of patients admitted for ACS due to improved electrocardiographic monitoring, early invasive management and newer anti-thrombotic therapies, long-term outcome of these patients remains relatively poor, especially for NSTE-ACS as compared to STEMI. The poorer outcome of NSTE-ACS compared with STEMI patients is due to the different characteristics of these two populations with a higher rate of diffuse coronary disease in patients with NSTE-ACS, who are often older and who present more comorbidities such as diabetes and renal failure. Despite these differences in longterm outcomes, physicians often consider NSTE-ACS as a "smaller MI" than STEMI because of the better short-term inhospital outcome and these patients are less frequently referred for coronary angiography and subsequent PCI [21]. Furthermore, the medical management for secondary prevention of ACS patients who do not benefit from an invasive approach is less frequently in accordance with recommendations than their invasively treated counterparts [31]. Of note, audits have demonstrated a gap between the ideal management of patients admitted to hospitals with an ACS and the actual received treatment and this is a major concern when aiming to improve the outcome of these patients [28]. In addition to the insufficient application of the recommended therapies by physicians, there is an important gap between medical prescription and patient therapeutic adhesion; this also has a significant impact on outcome including mortality. Following these observations, numerous quality improvement programs have been developed, which will be of importance considering the future projected reduction in hospital stay duration after an ACS. The latter is linked to progress in the acute care of ACS including early invasive approaches and the radial artery access for PCI with subsequent decrease of bleeding $[12,54,55]$. The results of the assessment of the ELIPS nation wide multi-dimensional quality improvement program for patients admitted to the hospital for an ACS are expected in 2013 .

Acknowledgments The study of the ELIPS program is supported by the Swiss National Science Foundation, by the De Reuter Foundation, and by Funds of the Department of Internal Medicine of the University Hospital and the Faculty of Medicine of Geneva; this fund receives an unrestricted grant from Astra-Zeneca Switzerland, GlaxoSmithKline and Merck Sharp \& Dohme.

\section{References}

1. Steg PG, Bhatt DL, Wilson PW, D'Agostino R Sr, Ohman EM, Röther J, et al. One-year cardiovascular event rates in outpatients with atherothrombosis. JAMA. 2007;297(11):1197-206.

2. Fox KA, Goodman SG, Klein W, Brieger D, Steg PG, Dabbous $\mathrm{O}$, et al. Management of acute coronary syndromes. Variations in practice and outcome; findings from the Global Registry of Acute Coronary Events (GRACE). Eur Heart J. 2002;23(15):1177-89.

3. Butler J, Arbogast PG, BeLue R, Daugherty J, Jain MK, Ray WA, et al. Outpatient adherence to beta-blocker therapy after acute myocardial infarction. J Am Coll Cardiol. 2002;40(9):1589-95. 
4. Smith CS, Cannon CP, McCabe CH, Murphy SA, Bentley J, Braunwald E. Early initiation of lipid-lowering therapy for acute coronary syndromes improves compliance with guideline recommendations: observations from the Orbofiban in Patients with Unstable Coronary Syndromes (OPUS-TIMI 16) trial. Am Heart J. 2005;149(3):444-50.

5. Ho PM, Spertus JA, Masoudi FA, Reid KJ, Peterson ED, Magid DJ, et al. Impact of medication therapy discontinuation on mortality after myocardial infarction. Arch Intern Med. 2006;166(17):1842-7.

6. Marciniak TA, Ellerbeck EF, Radford MJ, Kresowik TF, Gold JA, Krumholz HM, et al. Improving the quality of care for Medicare patients with acute myocardial infarction: results from the Cooperative Cardiovascular Project. JAMA. 1998;279(17):1351-7.

7. Fonarow GC, Gawlinski A, Moughrabi S, Tillisch JH. Improved treatment of coronary heart disease by implementation of a Cardiac Hospitalization Atherosclerosis Management Program (CHAMP). Am J Cardiol. 2001;87(7):819-22.

8. LaBresh KA, Ellrodt AG, Gliklich R, Liljestrand J, Peto R. Get with the guidelines for cardiovascular secondary prevention: pilot results. Arch Intern Med. 2004;164(2):203-9.

9. Lappe JM, Muhlestein JB, Lappé DL, Badger RS, Bair TL, Brockman R, et al. Improvements in 1-year cardiovascular clinical outcomes associated with a hospital-based discharge medication program. Ann Intern Med. 2004;141(6):446-53.

10. Eagle KA, Montoye CK, Riba AL, DeFranco AC, Parrish R, Skorcz S, et al. Guideline-based standardized care is associated with substantially lower mortality in medicare patients with acute myocardial infarction: the American College of Cardiology's Guidelines Applied in Practice (GAP) Projects in Michigan. J Am Coll Cardiol. 2005;46(7):1242-8.

11. Wood DA, Kotseva K, Connolly S, Jennings C, Mead A, Jones J, et al. Nurse-coordinated multidisciplinary, family-based cardiovascular disease prevention programme (EUROACTION) for patients with coronary heart disease and asymptomatic individuals at high risk of cardiovascular disease: a paired, cluster-randomised controlled trial. Lancet. 2008;371(9629): 1999-2012.

12. Auer R, Gaume J, Rodondi N, Cornuz J, Ghali WA. Efficacy of inhospital multidimensional interventions of secondary prevention after acute coronary syndrome: a systematic review and metaanalysis. Circulation. 2008;117(24):3109-17.

13. Ockene IS, Hayman LL, Pasternak RC, Schron E, Dunbar-Jacob J. Task force \#4-adherence issues and behavior changes: achieving a long-term solution. 33rd Bethesda Conference. J Am Coll Cardiol. 2002;40(4):630-40.

14. Krantz MJ, Baker WA, Estacio RO, Haynes DK, Mehler PS, Fonarow GC, et al. Comprehensive coronary artery disease care in a safety-net hospital: results of get with the guidelines quality improvement initiative. J Manag Care Pharm. 2007;13(4):319-25.

15. Granger CB, Steg PG, Peterson E, López-Sendón J, Van de Werf F, Kline-Rogers E, et al. Medication performance measures and mortality following acute coronary syndromes. Am J Med. 2005;118(8):858-65.

16. Tunstall-Pedoe H, Kuulasmaa K, Mähönen $M$, Tolonen $H$, Ruokokoski E, Amouyel P. Contribution of trends in survival and coronary-event rates to changes in coronary heart disease mortality: 10-year results from 37 WHO MONICA project populations. Monitoring trends and determinants in cardiovascular disease Lancet. 1999;353(9164):1547-57.

17. Goldberg RJ, Glatfelter K, Burbank-Schmidt E, Lessard D, Gore JM. Trends in community mortality due to coronary heart disease. Am Heart J. 2006;151(2):501-7.

18. Rogers WJ, Frederick PD, Stoehr E, Canto JG, Ornato JP, Gibson CM, et al. Trends in presenting characteristics and hospital mortality among patients with ST elevation and non-ST elevation myocardial infarction in the National Registry of Myocardial Infarction from 1990 to 2006. Am Heart J 2008;156(6):1026-34.
19. Braunwald E, Antman EM, Beasley JW, Califf RM, Cheitlin MD, Hochman JS, et al. ACC/AHA guidelines for the management of patients with unstable angina and non-ST-segment elevation myocardial infarction. A report of the American College of Cardiology/American Heart Association Task Force on Practice Guidelines (Committee on the Management of Patients With Unstable Angina). J Am Coll Cardiol. 2000;36(3):970-1062.

20. Vogel B, Hahne S, Kozanli I, Kalla K, Jarai R, Freynhofer M, et al. Influence of updated guidelines on short- and long-term mortality in patients with non-ST-segment elevation acute coronary syndrome (NSTE-ACS). Int J Cardiol. 2011; doi:10.1016/j. ijcard.2011.02.073

21. Terkelsen CJ, Lassen JF, Nørgaard BL, Gerdes JC, Jensen T, Gøtzsche LB, et al. Mortality rates in patients with ST-elevation vs. non-ST-elevation acute myocardial infarction: observations from an unselected cohort. Eur Heart J. 2005;26(1):18-26.

22. APEX AMI Investigators, Armstrong PW, Granger CB, Adams PX, Hamm C, Holmes D Jr, O'Neill WW, et al. Pexelizumab for acute ST-elevation myocardial infarction in patients undergoing primary percutaneous coronary intervention: a randomized controlled trial. JAMA. 2007;297(1):43-51.

23. Fox KA, Dabbous OH, Goldberg RJ, Pieper KS, Eagle KA, Van de Werf F, et al. Prediction of risk of death and myocardial infarction in the 6 months after presentation with acute coronary syndrome: prospective multinational observational study (GRACE). BMJ. 2006;333(7578):1091.

24. CURRENT-OASIS 7 Investigators, Mehta SR, Bassand JP, Chrolavicius S, Diaz R, Eikelboom JW, Fox KA, et al. Dose comparisons of clopidogrel and aspirin in acute coronary syndromes. N Engl J Med. 2010;363(10):930-42.

25. Primary versus tenecteplase-facilitated percutaneous coronary intervention in patients with ST-segment elevation acute myocardial infarction (ASSENT-4 PCI): randomised trial. Lancet. 2006; 367 (9510): 569-78.

26. Keller PF, Ibrahim R, Tardif JC. The drug-based pipeline against restenosis. Expert Opin Emerg Drugs. 2005;10(1):67-86.

27. Cutlip DE, Chhabra AG, Baim DS, Chauhan MS, Marulkar S, Massaro J, et al. Beyond restenosis: five-year clinical outcomes from second-generation coronary stent trials. Circulation. 2004;110(10):1226-30.

28. Steg PG, Goldberg RJ, Gore JM, Fox KA, Eagle KA, Flather MD, et al. Baseline characteristics, management practices, and in-hospital outcomes of patients hospitalized with acute coronary syndromes in the Global Registry of Acute Coronary Events (GRACE). Am J Cardiol. 2002;90(4):358-63.

29. Tuppin Neumann A, Danchin N, de Peretti C, Weill A, Ricordeau $\mathrm{P}$, et al. Evidence-based pharmacotherapy after myocardial infarction in France: Adherence-associated factors and relationship with 30-month mortality and rehospitalization. Arch Cardiovasc Dis. 2010; 103:363-75.

30. Peterson ED, Shah BR, Parsons L, Pollack CV Jr, French WJ, Canto JG, et al. Trends in quality of care for patients with acute myocardial infarction in the National Registry of Myocardial Infarction from 1990 to 2006. Am Heart J 2008;156(6):1045-55.

31. Danchin N, Grenier O, Ferrières J, Cantet C, Cambou JP. Use of secondary preventive drugs in patients with acute coronary syndromes treated medically or with coronary angioplasty: results from the nationwide French PREVENIR survey. Heart. 2002;88 (2):159-62.

32. Montoye CK, Mehta RH, Baker PL, Orza M, Elma MA, Parrish R, et al. A rapid-cycle collaborative model to promote guidelines for acute myocardial infarction. Jt Comm J Qual Saf. 2003;29(9):468-78.

33. Mehta RH, Montoye CK, Faul J, Nagle DJ, Kure J, Raj E, et al. Enhancing quality of care for acute myocardial infarction: shifting the focus of improvement from key indicators to process of care and tool use: the American College of Cardiology Acute 
Myocardial Infarction Guidelines Applied in Practice Project in Michigan: Flint and Saginaw Expansion. J Am Coll Cardiol. 2004;43(12):2166-73.

34. Muller-Riemenschneider F, Meinhard C, Damm K, Vauth C, Bockelbrink A, Greiner W, et al. Effectiveness of nonpharmacological secondary prevention of coronary heart disease. Eur J Cardiovasc Prev Rehabil. 2010;17(6):688-700.

35. Rigotti NA, Munafo MR, Stead LF. Interventions for smoking cessation in hospitalised patients. Cochrane Database Syst Rev. 2007;18(3): CD001837.

36. Taylor RS, Brown A, Ebrahim S, Jolliffe J, Noorani H, Rees K, et al. Exercise-based rehabilitation for patients with coronary heart disease: systematic review and meta-analysis of randomized controlled trials. Am J Med. 2004;116(10):682-92.

37. Bassand JP, Hamm CW, Ardissino D, Boersma E, Budaj A, Fernández-Avilés F, et al. Guidelines for the diagnosis and treatment of non-ST-segment elevation acute coronary syndromes. Eur Heart J. 2007;28(13):1598-660.

38. Bjarnason-Wehrens B, McGee H, Zwisler AD, Piepoli MF, Benzer W, Schmid JP, et al. Cardiac rehabilitation in Europe: results from the European Cardiac Rehabilitation Inventory Survey. Eur J Cardiovasc Prev Rehabil. 2010;17(4):410-8.

39. Jackevicius CA, Mamdani M, Tu JV. Adherence with statin therapy in elderly patients with and without acute coronary syndromes. JAMA. 2002;288(4):462-7.

40. Cramer JA, Roy A, Burrell A, Fairchild CJ, Fuldeore MJ, Ollendorf DA, et al. Medication compliance and persistence: terminology and definitions. Value Health. 2008;11(1):44-7.

41. Haynes RB, McDonald HP, Garg AX. Helping patients follow prescribed treatment: clinical applications. JAMA. 2002;288 (22):2880-3.

42. Benner JS, Glynn RJ, Mogun H, Neumann PJ, Weinstein MC, Avorn J. Long-term persistence in use of statin therapy in elderly patients. JAMA. 2002;288(4):455-61.

43. Ammassari A, Trotta MP, Murri R, Castelli F, Narciso P, Noto P, et al. Correlates and predictors of adherence to highly active antiretroviral therapy: overview of published literature. J Acquir Immune Defic Syndr. 2002;31 Suppl 3:S123-7.

44. Sewitch MJ, Abrahamowicz M, Barkun A, Bitton A, Wild GE, Cohen A, et al. Patient nonadherence tomedication in inflammatory bowel disease. Am J Gastroenterol. 2003;98(7):1535-44.

45. Lacro JP, Dunn LB, Dolder CR, Leckband SG, Jeste DV. Prevalence of and risk factors for medication nonadherence in patients with schizophrenia: a comprehensive review of recent literature. J Clin Psychiatry. 2002;63(10):892-909.

46. van Servellen G, Chang B, Garcia L, Lombardi E. Individual and system level factors associated with treatment nonadherence in human immunodeficiency virus-infected men and women. AIDS Patient Care STDS. 2002;16(6):269-81.

47. Okuno J, Yanagi H, Tomura S. Is cognitive impairment a risk factor for poor compliance among Japanese elderly in the community? Eur J Clin Pharmacol. 2001;57(8):589-94.

48. Perkins DO. Predictors of noncompliance in patients with schizophrenia. J Clin Psychiatry. 2002;63(12):1121-8.

49. Balkrishnan R. Predictors of medication adherence in the elderly. Clin Ther. 1998;20(4):764-71.

50. Ellis JJ, Erickson SR, Stevenson JG, Bernstein SJ, Stiles RA, Fendrick AM. Suboptimal statin adherence and discontinuation in primary and secondary prevention populations. J Gen Intern Med. 2004;19(6):638-45.

51. Farley J, Hines S, Musk A, Ferrus S, Tepper V. Assessment of adherence to antiviral therapy in HIV-infected children using the Medication Event Monitoring System, pharmacy refill, provider assessment, caregiver self-report, and appointment keeping. J Acquir Immune Defic Syndr. 2003;33(2):211-8.

52. Stilley CS, Sereika S, Muldoon MF, Ryan CM, Dunbar-Jacob J. Psychological and cognitive function: predictors of adherence with cholesterol lowering treatment. Ann Behav Med. 2004;27 (2): $117-24$

53. Osterberg L, Blaschke T. Adherence to medication. N Engl J Med. 2005;353(5):487-97.

54. Rinfret S, Kennedy WA, Lachaine J, Lemay A, Rodés-Cabau J, Cohen DJ, et al. Economic impact of same-day home discharge after uncomplicated transradial percutaneous coronary intervention and bolus-only abciximab regimen. JACC Cardiovasc Interv. 2010;3(10):1011-9.

55. Jolly SS, Yusuf S, Cairns J, Niemelä K, Xavier D, Widimsky P, et al. Radial versus femoral access for coronary angiography and intervention in patients with acute coronary syndromes (RIVAL): a randomised, parallel group, multicentre trial. Lancet. 2011; 377:1409-20.

56. Jacobs AK, Antman EM, Ellrodt G, Faxon DP, Gregory T, Mensah GA, et al. Recommendation to develop strategies to increase the number of ST-segment-elevation myocardial infarction patients with timely access to primary percutaneous coronary intervention. Circulation. 2006;113(17):2152-63. 